Full length article

\title{
A comparative life-cycle assessment of asphalt mixtures for railway sub-ballast containing alternative materials
}

\author{
Sara Bressi ${ }^{\mathrm{a}, *}$, Joao Santos ${ }^{\mathrm{b}}$, Marinella Giunta ${ }^{\mathrm{c}}$, Lavinia Pistonesi ${ }^{\mathrm{a}}$, Davide Lo Presti ${ }^{\mathrm{d}}$ \\ ${ }^{a}$ Department of Civil and Industrial Engineering (DICE), University of Pisa, Italy \\ ${ }^{b}$ Department of Construction Management \& Engineering, Faculty of Engineering Technology, University of Twente, Enschede, The Netherlands \\ ${ }^{c}$ Department of Civil, Energy, Environmental and Material Engineering (DICEAM), University Mediterranea of Reggio Calabria, Reggio Calabria, Italy
}

${ }^{d}$ Nottingham Transportation Engineering Centre, University of Nottingham Faculty of Engineering, The University of Nottingham, University Park, Nottingham, NG7 2RD, United Kingdom

\section{A R T I C L E IN F O}

\section{Keywords:}

Bituminous mixtures

Crumb rubber

Reclaimed asphalt pavements

Life-cycle assessment

Environmental sustainability

\begin{abstract}
A B S T R A C T
Bituminous sub-ballast in railway track-bed can mitigate the variation of the moisture content in the subgrade and reduce vertical stiffness variations of the track leading to a more durable infrastructure. Nevertheless, durability is only one of the aspects that affects the sustainability of an infrastructure. Other relevant aspects are related to the environmental and economic issues. This research work joins the worldwide effort towards a paradigm shift in civil engineering devoted to assess the sustainability of infrastructures at the design stage. With this in mind, in this study different alternative bituminous sub-ballast mixtures containing recycled materials, namely crumb rubber (CR) and reclaimed asphalt pavements (RAP) were compared by means of the results of a Life-Cycle Assessment (LCA). In comparison with a traditional bituminous sub-ballast the Crumb Rubber Modified (CRM) mixtures showed higher impacts due to the treatment of the rubber as well as the higher amount of bitumen employed in the mixture. In turn, when RAP is used, the LCA results report an improvement of all the indicators considered. The reduction of the impacts is even higher when full blending between the aged and the virgin binder is assumed because it allows reducing the amount of virgin bitumen employed. The results are intended to be used by engineering experts and practitioners to make more assertive judgments on the advantages and disadvantages associated with the use of emerging and commonly called sustainable strategies and practices for railway track-bed.
\end{abstract}

\section{Introduction}

Railway transport is one of the transport modes responsible for the lowest $\mathrm{CO}_{2}$ emissions and energy consumption when operational components, such as running vehicles, are considered. However, during the construction and maintenance operations (non-operational components) the $\mathrm{CO}_{2}$ emission and energy consumption are considerably high comparatively to other transport modes (Chester and Horvath, 2009; Schwarz, 2009). This gap between energy consumption and Greenhouse Gas (GHG) emissions related to operational and non-operational components underline the need for further research efforts dedicated to the improvement of the best practices of construction and maintenance of railway infrastructures, in order to minimize their negative effects on the society and environment. Railway track-bed is typically com- posed of different layers, namely ballast, sub-ballast and subgrade. Each layer plays an important role for the durability and maintenance of the track geometry. The use of natural aggregates for constructing those layers represents a significant consumption of an important non-renewable resource that is becoming increasingly scarce. Using recycled materials in the construction and maintenance of railway track-bed can significantly reduce the consumption of natural resources and mitigate the need for the disposal of a solid waste.

In the last years, the growing popularity of recycled materials applied in road pavements and railway infrastructures, such as crumb rubber (CR) coming from end-of-life tires (ELTs), and reclaimed asphalt pavement (RAP) has sparked the conduction of several studies aiming at improving the recycling of materials, in which the waste produced by some systems reduces the consumption of primary materials being needed by other ones as for instance the production of asphalt mixtures (Silva et al., 2012; Bressi et al., 2016).

\footnotetext{
* Corresponding author.

Email addresses: sara.bressi@ing.unipi.it (S. Bressi); j.m.oliveiradossantos@utwente.nl (J. Santos); marinella.giunta@unirc.it (M. Giunta)
} 
ELTs are among the largest and most problematic sources of waste due to the large volume produced and their durability (Lo Presti, 2013). On one hand, these characteristics are negative if ELTs are considered as waste material, but being very resistant and durable, CR obtained from the processing of ELTs has the potential to be an interesting material for use in other products, such as asphalt mixtures. Rubber grains are obtained from crushing scrap tires in specialized plants where they are also separated from steel fibers and textile. These grains can be incorporated into the preparation of asphalt mixtures by the so-called "wet" and "dry" production processes. The wet process envisages the dissolution of the $\mathrm{CR}$ in the bitumen as a modifying agent. The dry process envisages the replacement of a small portion of aggregates with the same fractions of rubber grains (FHWA, 1997).

The dry process became recently a very attractive technology because of its production simplicity compared to the wet process (Feiteira Dias et al., 2014). Indeed, the crumb rubber is added directly to the aggregates during the fabrication as another ingredient in the mix. The bitumen is then modified when it comes in contact with the rubber (CEDEX, 2007). When the rubber is added to the asphalt mixture by means of dry process the grains of rubber swell up because they absorb part of the volatile parts of bitumen (paraffin and maltenes). This process of maturation, called "maceration", led to obtain a stiffer bitumen (Dong et al., 2012), increasing the quantity of bitumen necessary to achieve the mix design optimization of the CR mixtures.

The use of CR in the production of asphalt mixtures by means of both technologies (wet and dry process) has proved to be environmentally beneficial due to: (i) the reduction of the Gross Energy Requirement (GER) and the GHG emissions (Farina et al., 2016); (ii) the reduction of noise, especially when the dry process is used (Paje et al., 2010); and (iii) the improvement of damping properties when CR is mixed as an aggregate as a consequence of the vibrations absorption by the rubber (D'Andrea et al., 2004).

RAP is the milled material coming from the Maintenance and Rehabilitation (M\&R) of asphalt pavements. The opportunity for using high amounts of RAP is underscored by the need of reducing the exploitation of quarries and the disposal of wastes resulting from rehabilitation projects of road pavements. Often, these materials can be used to replace virgin materials that are more expensive, provided that they ensure the same performance level as the traditional ones. This aspect seems not to be a practical limitation, given that several research works have proven that significant quantities of RAP can be employed while keeping an acceptable level of performance (Santero et al., 2011; Yu and Lu, 2012; Praticò et al., 2013; Bressi et al., 2016). Moreover, the use of RAP to fully or partially replace virgin and/or manufactured materials, thus avoiding their landfill or stockpile as waste, it is also attractive for highway agencies to the extent that it reduces the cost of purchasing and transporting new aggregate and binder for asphalt mixtures.

\section{Objective and methodology}

The objective of this paper is to perform a comparative life-cycle assessment (LCA) of traditional bituminous mixtures for sub-ballast, produced following the Italian standard specification of Rete Ferroviarie Italiane (RFI), and bituminous sub-ballast mixtures containing different percentages of recycled materials (i.e., RAP and CR).

In order to ascertain the extent to which the alternative sub-ballast mixtures allow achieving environmental benefits when compared to the traditional sub-ballast mixtures, it is crucial to adopt a Life-Cycle approach able to identify and quantify the potential environmental burdens arising from the use of these solutions. This need can be accomplished with the support of the LCA methodology (ISO, 2006a) and the most recent standard on "Sustainability of Construction works" (EN 15804, 2012). LCA, which is a data-driven, systematic methodology, has proven to be effective in estimating the environmental burdens caused by a product, process, or service throughout its Life-Cycle (Matthews et al., 2015). Among other capabilities, LCA assesses the potential impacts of the emissions released to the environment as a consequence of the energy and materials consumed and identifies opportunities for environmental improvements. The assessment includes the entire Life-Cycle of the product, process, or service and encompasses the extraction and processing of raw materials, manufacturing, transportation, maintenance, use, and end-of-life (Consoli et al., 1993). According to the ISO 14040 series the LCA framework is divided into four stages (ISO, 2006a, b): (i) goal and scope definition; (ii) Life-Cycle inventory analysis (LCI); (iii) Life-Cycle impact assessment (LCIA); and (iv) interpretation.

\subsection{Goal and scope definition}

\subsubsection{Goal}

The main goal of this research work is to quantify the potential Life-Cycle environmental impacts arising from the use of different types of alternative materials in the bituminous sub-ballast layer, specifically CR obtained from processing ELTs and RAP coming from the demolition of old road pavements. The results are compared with those associated with the use of traditional sub-ballast mixtures. The findings of this study are intended to be used by engineering experts and practitioners to make more assertive judgments on the advantages and disadvantages associated with the use of emerging and commonly called sustainable strategies and practices for railway track-bed construction and M\&R.

The ReCiPe method (Goedkoop et al., 2013) was used to assess the potential environmental impacts. This allowed covering several environmental interests because a list of LCI outputs are transformed into values of indicators that are related to environmental impact categories. The analyses were performed by using Gabi Professional Academy LCA software ${ }^{\circledR}$ (Gabi ts, 2017) and its database and processes. Specific processes not available in Gabi (for instance CR production) were purposely created.

\subsubsection{System description and boundaries}

The system includes within its boundaries all the activities required to construct the bituminous sub-ballast layer. Specifically, the following phases are accounted for: (i) resources extraction and composite materials production; (ii) movement involved in hauling materials between facilities and work site; and (iii) construction equipment operation during the construction of the sub-ballast layer. The system boundaries tailored for the specific application carried out in this research work take into account the existing literature about the durability and performance of bituminous mixtures containing CR (dry process) and/ or RAP. In this context, according to several recent studies (Farina et al., 2016; Lee et al., 2008; Fontes et al., 2010; Pinheiro and Soares, 2003; Gowda et al., 1996; Tam et al., 1992; McDaniel et al., 2000), CR dry and RAP mixtures can achieve the same performances of a traditional mixture, while few others instead report higher performance (Olivares et al., 2009; Airey et al., 2003; Sargious and Mushule, 1991; Huang et al., 2004). In particular, the dry technology analyzed in this paper is called RUMAC and usually contains $1-3$ percent of rubber by weight of the total aggregate in the mix and target air voids content 2-4 percent (FHWA-RD-97-148). In the 1980's the mix design and the technology was refined achieving the production of a bituminous mixture commercially called PlusRide (Kandhal and Hanson, 1993). This type of mixture has been tested several times in test sections showing contradictory results. For instance, the California Department of Transportation (CalTrans, 2006) has constructed four projects using the dry process technology and the results were that two of the four dry process projects improved the performance of traditional dense-graded 
asphalt, a third project has performed comparably and the last showed worse results (Kirk and Jack, 1991). Moreover, the two dry process sections constructed by the Minnesota Department of Transportation (MNDOT) have not shown higher performance compared to traditional asphalt (Turgeon and Curtis, 1989).

Therefore, a conservative approach assuming the same durability for all the solutions is considered. That means that the maintenance, dismantling and disposal phases are scheduled at the same time for all the solutions and then are excluded from the system boundaries. Indeed, a cradle-to-gate model is appropriate, excluding other phases of the compared systems, when the materials do not differ in durability, i.e. they have same transport implications, maintenance and EOL management (EC, JRC - IES, 2010). This approach has been adopted also in recent studies for comparing infrastructures materials with RAP, when the durability was similar (Porot et al., 2016). Usually, the use of RAP percentages below $30-40 \%$ do not require specific technologies such as separate parallel drum or the use of additives to overcome technical issues (Porot et al., 2016). These percentages allow achieving the same durability of traditional mixtures, without the employment of particular technologies, therefore a cradle-to-gate approach has been assumed.

The resources extraction and composite materials production consists of the acquisition and processing of raw materials, such as the bitumen production at refinery; extraction, crushing and sieving of aggregates, acquisition of crumb rubber generated as a by-product of the scrap tires crushing and sieving, and RAP processing.

The mixing process of asphalt mixtures takes place in hot mix production plants where bitumen is heated and pumped. Virgin aggregates are washed, dried, heated and added to the mixture, crumb rubber is added at room temperature while RAP is heated at lower temperature compared to the virgin aggregates. Indeed, it is important to heat the RAP as little as possible, as the heating ages the already aged binder further (Bressi et al., 2016).

All the components are mixed in a batch-type mixing plant at the mixing temperature of $180^{\circ} \mathrm{C}$. Afterwards, when the materials arrive at the construction site they are laid down with specific construction equipment and machinery, such as standard pavers and rollers. The transportation of materials to and from the construction site and between intermediate facilities are also considered.

\subsubsection{Functional unit}

The case study presented in this paper is referring to the railway track line between Florence and Viareggio in the Pistoia-Montecatini
Terme section, Italy. The functional unit is a sub-ballast layer with a length of $1 \mathrm{~km}$, a thickness of $12 \mathrm{~cm}$ and a width of $12.7 \mathrm{~m}$. The thickness is equal for all the alternatives since it was assumed that all the solutions have the same durability. Fig. 1 shows the position of the railway track-line of the case study.

\subsubsection{Asphalt mixtures types and composition}

Five types of bituminous mixtures for sub-ballast were considered in the application: the traditional mixture, complying with the RFI standard (RFI, 2016), and four mixtures with recycled materials, i.e., CR and RAP. In order to understand the potential environmental advantages and disadvantages related to the use of asphalt mixtures with recycled materials, mixtures with different percentages of RAP and CR were considered and compared with the reference scenario corresponding to the production and placement of a classical bituminous sub-ballast mixture named RFI with $4 \%$ of bitumen by weight of mixture. The mixtures considered have the features described in the following:

- DRY1.5. Rubberized asphalt (dry process) containing 1.5\% of CR and $5.5 \%$ of bitumen (both by weight of mixture).

- DRY2.0 Rubberized asphalt (dry process) containing 2.0\% of CR and $6.0 \%$ of bitumen (both by weight of mixture).

- RAP30BR bituminous sub-ballast with $30 \%$ of RAP in partial substitution of virgin aggregates. This scenario considers that the bitumen trapped in RAP behaves as black rock (Shirodkar et al., 2010) not active in the new asphalt mixture. Black rock scenario corresponds to the $0 \%$ blending between RAP and virgin binder. Therefore, the percentage of the virgin bitumen to be added to the mixture cannot be reduced and has been kept equal to $4 \%$.

- RAP30FB bituminous sub-ballast with 30\% of RAP in partial substitution of virgin aggregates. This scenario considers $100 \%$ of aged bitumen trapped in the RAP being reactivated. The full blending between the RAP and virgin binder allows reducing the portion of virgin bitumen. Indeed, if RAP contains $5.5 \%$ of bitumen, it is necessary to add $3.3 \%$ of virgin bitumen in order to have a final content of $4 \%$ of total bitumen.

The composition of DRY1.5 and DRY2.0 results from a mix design optimization conducted in previous studies where it is shown also that higher amount of rubber can inhibit a satisfactory compaction in the laboratory due to the elastic behavior of the rubber (Bressi et al., 2018). For this reason, higher percentages of rubber were not consid-

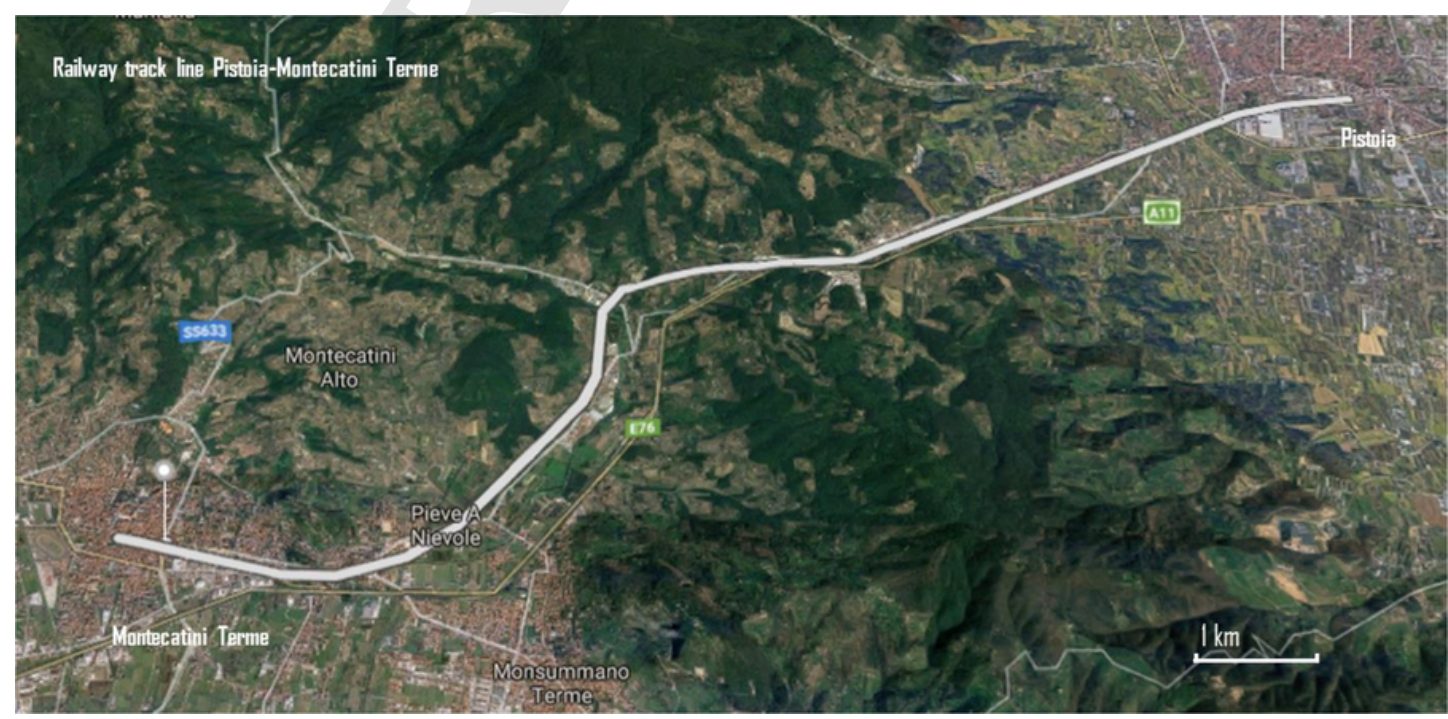

Fig. 1. Railway track line Pistoia - Montecatini Terme. 
ered. Moreover, the absorption of bitumen caused by the rubber represents the main reason of the different mix design approach and the different bitumen quantity necessary for optimizing the recipe of the bituminous mixture containing CR.

Table 1 summarizes the composition of each bituminous mixture used as an alternative to the traditional bituminous sub-ballast (RFI) by showing the quantities of every element used to produce each alternative.

\subsection{Life-cycle inventory}

The life cycle inventory (LCI) phase consists of the primary and secondary data collection and modelling of the system. Primary data are specifically related to the processes for obtaining the product or service studied in the LCA. In turn, secondary data represent generic or average data for the product or service subject to analysis. The provenience of that data includes literature, research groups, national and international database and expert's opinion (EC, JRC - IES, 2010). In the present work both primary and secondary data have been considered as detailed in the following sub-paragraphs. The data sources were selected in order to be as much time, geographical and technological representative as possible. That means that the most recent and truthful data representing Italian processes and conditions were used as inputs and outputs when modelling the processes covered by the sub-components integrating the system boundaries. The Ecopneus document (Ecopneus, 2013) was used as main reference for conducting the LCI of asphalt mixtures containing alternative materials. Reference values for the productivity and working hours of the machinery (pavers and rollers) considered for the laying down operations and compaction of the sub-ballast layers were collected from literature (Autostrade per l'Italia, 2011). For completing the data set and modelling the back-

Table 1

Composition of the different bituminous mixtures used in the sub-ballast layer.

\begin{tabular}{|c|c|c|c|c|}
\hline $\begin{array}{l}\text { Type of } \\
\text { mixture }\end{array}$ & $\begin{array}{l}\text { Quantity } \\
\text { of } \\
\text { bitumen } \\
\text { (kg per } \\
\text { ton of } \\
\text { mixture) }\end{array}$ & $\begin{array}{l}\text { Quantity } \\
\text { of } \\
\text { aggregates } \\
\text { (kg per } \\
\text { ton of } \\
\text { mixture) }\end{array}$ & $\begin{array}{l}\text { Quantity } \\
\text { of CR } \\
\text { (kg per } \\
\text { ton of } \\
\text { mixture) }\end{array}$ & $\begin{array}{l}\text { Quantity } \\
\text { of RAP } \\
\text { (kg per } \\
\text { ton of } \\
\text { mixture) }\end{array}$ \\
\hline RFI mixture & 40 & 960 & 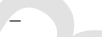 & - \\
\hline $\begin{array}{l}\text { DRY1.5 } \\
\text { rubberized } \\
\text { mixture with } \\
1.5 \%\end{array}$ & 55 & 930 & 15 & - \\
\hline $\begin{array}{l}\text { DRY2.0 } \\
\text { rubberized } \\
\text { mixture with } \\
2.0 \%\end{array}$ & 60 & 920 & 20 & - \\
\hline $\begin{array}{l}\text { RAP30BR } \\
\text { with } 30 \% \text { of } \\
\text { RAP by } \\
\text { weight of } \\
\text { aggregates } \\
\text { and black } \\
\text { rock (aged } \\
\text { binder not } \\
\text { reactivated) }\end{array}$ & 40 & 672 & - & 288 \\
\hline $\begin{array}{l}\text { RAP30FB } \\
\text { with } 30 \% \text { of } \\
\text { RAP by } \\
\text { weight of } \\
\text { aggregates } \\
\text { and full } \\
\text { blending } \\
\text { (aged binder } \\
\text { totally } \\
\text { reactivated) }\end{array}$ & 33 & 677 & - & 290 \\
\hline
\end{tabular}

ground system the Construction materials (CM) database extension of Gabi software was used.

\subsubsection{Materials extraction and composite materials production phase}

2.2.1.1. Virgin aggregates and bitumen production sub-phase The virgin aggregates required for the sub-ballast were modelled as crushed gravel and the inventory data associated with their production were obtained from the CM database: Limestone, crushed gravel, grain size 2/ $16 \mathrm{~mm}$. For modeling the production of sub-ballast material, it is necessary to model the production of bitumen. The CM database was also used as the data source for modelling the bitumen production. It comprises all the flows of materials and energy associated with the extraction in the quarry, the cleaning, the two stages of crushing, the organization of the production and the transport. The finished product is the crushed gravel (dried) at the factory gate.

2.2.1.2. Crumb rubber production sub-phase Normally CR particles are obtained by reducing ELTs to small size grains (typically ranging from $4.75 \mathrm{~mm}$ to $0.075 \mathrm{~mm}$ ) and removing the steel and textile from the scrap tires. One of the most common process to manufacture CR is the ambient grinding, i.e. a multi-step technology where tire chips are crushed in mills at ambient temperature (Shu and Huang, 2014). The chips are fed into a granulator that breaks them into small pieces. Afterwards, remaining steel is removed magnetically while for the fiber a combination of shaking screens and wind sifters are used.

In the $C M$ database, the process related to the production of $\mathrm{CR}$ is not available. Therefore, a new process crumb rubber was created by collecting information from a recent study conducted by Ecopneus (2013). A Cut-off approach was adopted for the evaluation of the burdens and benefits associated to the use of the recycled material. According to the Cut-off approach specified by the General Guide for Life-Cycle Assessment (European Commission, 2010a,b), only the burdens directly associated with the product itself are accounted for. Therefore, for the recycled materials derived from the ELTs the environmental impacts of the following processes were taken into account: (i) transport of materials from the collection platform to the recycling plant (crushing plant); (ii) the recycling process, including crushing and separation of the fibers and metal from the rubber; (iii) the sieving of different fractions; and (iv) the transport from the recycling plant to the hot mix asphalt plant. For the creation of the crumb rubber production process, it was necessary to build other two sub-processes: Plastic big-bag production to collect the CR grains after sieving (Fig. 2a) and Steel blade to crush the scrap tires conveyed in the batch through a conveyor belt. (Fig. 2b).

It was assumed that the Plastic big-bag used for collecting the different fractions of rubber grains are composed of $90 \%$ of polypropylene and $10 \%$ of polyethylene. The process contains all the operations and burdens for the transformation of raw plastic into the final product. The LCI of the plastic big bag production was collected from recent studies (Ruban, 2012; Pistonesi, 2017) and summarized in Table 2.

The data for the modules Polyethylene foam [Plastics], Polyethylene low density granulate (LDPE/PE-LD) [Plastics] and Polypropylene granulate (PP) [Plastics] include the production of the raw material. Thus all the processes from the resource extraction, acquisition and processing of raw materials were taken into account. Emissions to water and air are not tracked by the original modules, and then were gathered from a study conducted by Ruban (2012).

For the steel blade the processes selected are as follows: (i) steel production; (ii) hot rolling; and (iii) sheet rolling. The data set represents the steel production based on the main production steps, which take place within an integrated steel plant. The LCI of steel blade was collected from recent studies (Farina et al., 2016; Pistonesi, 2017) and it is covered by the processes IT: electricity mix [supply mix] $(0.00103 \mathrm{MJ})$, Steel, converter, unalloyed, at plant, Sheet rolling, steel [processing] present in CM database. 


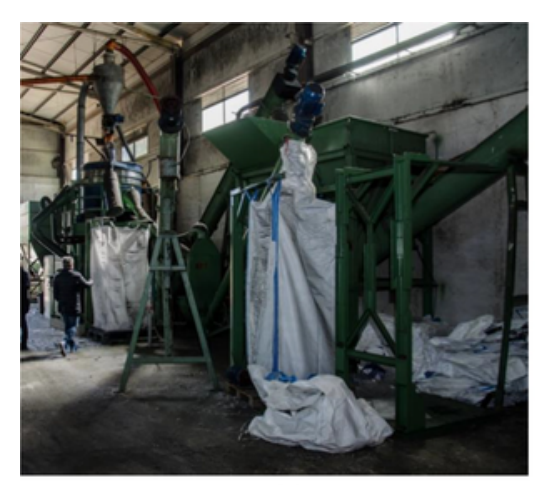

(a)

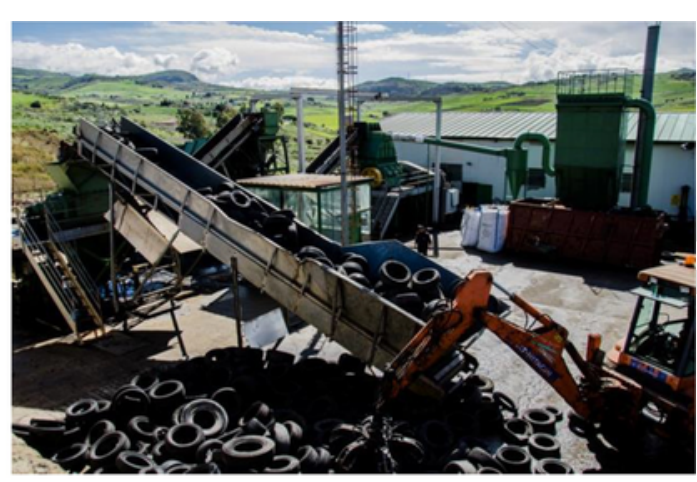

(b)

Fig. 2. a) Mill and big bag to collect the rubber fractions and b) crushing process at the plant.

Table 2

Inventory referring to the production of $1 \mathrm{~kg}$ of Plastic big-bag.

\begin{tabular}{|c|c|c|}
\hline Input Item & Quantity & Unit \\
\hline Diesel [Refinery products] ${ }^{\mathrm{a}}$ & $6,81 \mathrm{E}-05$ & $\mathrm{~kg}$ \\
\hline Polyethylene foam [Plastics] ${ }^{\mathrm{b}}$ & 1 & $\mathrm{~kg}$ \\
\hline $\begin{array}{l}\text { Polyethylene low density granulate (LDPE/PE-LD) } \\
\text { [Plastics] }^{\text {b }}\end{array}$ & 0,1 & $\mathrm{~kg}$ \\
\hline Polypropylene granulate (PP) [Plastics $]^{\mathrm{b}}$ & 0,9 & $\mathrm{~kg}$ \\
\hline Emissions to air and water & Quantity & Unit \\
\hline Butyl acetate [ecoinvent long-term to air] ${ }^{\mathrm{a}}$ & 0,0097 & $\mathrm{~kg}$ \\
\hline Carbon dioxide [Inorganic emissions to air] ${ }^{\mathrm{a}}$ & 0,00041 & $\mathrm{~kg}$ \\
\hline Carbon monoxide [Inorganic emissions to air] ${ }^{\mathrm{a}}$ & $8,06 \mathrm{E}-06$ & $\mathrm{~kg}$ \\
\hline Ethanol [ecoinvent long-term to air] ${ }^{\mathrm{a}}$ & 0,00194 & $\mathrm{~kg}$ \\
\hline Methane [Organic emissions to fresh water ${ }^{\mathrm{a}}$ & $3,26 \mathrm{E}-08$ & $\mathrm{~kg}$ \\
\hline Nitrogen dioxide [Inorganic emissions to air] ${ }^{\mathrm{a}}$ & 4,10E-06 & $\mathrm{kg}$ \\
\hline Sulphur oxides [Inorganic emissions to air ${ }^{\mathrm{a}}$ & $5,00 \mathrm{E}-07$ & $\mathrm{~kg}$ \\
\hline Toluene [ecoinvent long-term to air] ${ }^{\mathrm{a}}$ & 0,00399 & $\mathrm{~kg}$ \\
\hline
\end{tabular}

Notes: aRuban (2012); ${ }^{b}$ Pistonesi (2017).

These processes include the production of unalloyed steel, the transportation of the hot steel and other materials to the converter and the operation for pouring the melted steel into the mould. All the operations for heating, rolling and transforming the steel in a metallic sheet were also considered.

Once the processes Steel blade and Plastic Big-Bag production were created, they were included in the crumb rubber process. The input/output flows of materials and energy sources were calculated as the average value of the data collected from the Italian crushing plants.

The crumb rubber production is a multi-output process. Indeed, from the scrap tires treatment in specialized plants three main elements can be obtained: (i) CR (that will be used in the asphalt mixture); (ii) scrap steel; and (iii) textile. Therefore, the allocation of all the outputs was conducted according to the mass approach by using the following percentages: CR 69\%, scrap steel output $20 \%$ and textile output $11 \%$ (Farina et al., 2016). Despite the high market value of steel, steel scrap was not assumed to undergo recycling for the high operational complexity of separating the scrap steel from residual rubber. Table 3 summarizes the input and output flows of the crumb rubber production process for producing $15 \mathrm{~kg}$ of rubber ( $1.5 \%$ of 1 ton of bituminous mixture). 2.2.1.3. RAP production sub-phase Also for RAP production the cut-off approach was adopted. In this case study, it was considered that once removed from road pavement, the RAP is transported directly to the hot mix asphalt plant where it is stored in special sites and subjected to screening and down-sizing operations. For the RAP handling, the common production rates of the several machines integrating the processing unit were considered when determining the energy requirements.
Table 3

Input and output flows associated with the crumb rubber process.

\begin{tabular}{lll}
\hline Input flow & Quantity & Unit \\
\hline Plastic big bag & 0.028 & $\mathrm{Kg}$ \\
Diesel mix at refinery EU-28 $^{\mathrm{a}}$ & 0.038 & $\mathrm{Kg}$ \\
IT: Electricity mix grid production ${ }^{\mathrm{b}}$ & 20.7 & $\mathrm{MJ}$ \\
Lubricating oil & 0.001 & $\mathrm{Kg}$ \\
Tap water, at user & 3.3 & $\mathrm{Kg}$ \\
Steel blade & 0.004 & $\mathrm{Kg}$ \\
Conveyor belt, at plant & $9.5 \mathrm{E}-005$ & $\mathrm{~m}$ \\
Scrap tires & 21.8 & $\mathrm{Kg}$ \\
\hline Output flows & & $\mathrm{Unit}$ \\
\hline CR (module created) & Quantity & $\mathrm{Kg}$ \\
Recycled fibers & \multicolumn{2}{c}{$\mathrm{Kg}$} \\
Steel scrap product & 15 & $\mathrm{Kg}$ \\
\hline
\end{tabular}

Notes: ${ }^{a}$ This module includes the steam treatment and allows quantifying all the output of the diesel production; ${ }^{b}$ It refers to the production and importation of energy in Italy, including all types of energy. It includes also losses, calculated as average values.

The LCI data related to the production and distribution of those energy resources were taken from the CM database. Moreover, the treatment of the RAP at the plant requires a certain amount of energy for sieving and eventually crushing the recycled material. This amount of energy was considered to be equal to $0.0212 \mathrm{MJ}$ per $\mathrm{kg}$ of RAP (Zaumanis et al., 2012).

2.2.1.4. Asphalt mixtures production sub-phase The mixture production activities take place in the hot mix production plant. The processes crumb rubber production, aggregates production, RAP production and bitumen production already described were created and fed into the process for the production of bituminous sub-ballast mixtures.

The electricity for the production of 1 ton of sub-ballast mixture was equal to $160 \mathrm{kWh}$ (Ecopneus, 2013) and it was assumed to be the same for all the solutions because the fabrication temperature is considered to be the same (Farina et al., 2016). In this case study the electricity is used to power a discontinuous batch with a gas burner with a power of $580 \mathrm{~kW}$.

\subsubsection{Construction phase}

To build a layer of bituminous sub-ballast in a railway track it is necessary to lay down the bituminous mixture with a paver and compact it in order to achieve the desired thickness of $12 \mathrm{~cm}$. The fuel combustion-related emissions associated with the operation of each construction equipment were determined by combining the LCI data corresponding to the process "machine operation, diesel, $>=74.57 \mathrm{~kW}$, high load factor | machine operation, diesel, $>=74.57 \mathrm{~kW}$, high load factor" existing in the $C M$ database with an hourly productivity of $150 \mathrm{t} / \mathrm{h}$ for the operations involved in pavement construction activities. By consid- 
ering respectively fuel consumption rates of 0.21 and $0.121 / \mathrm{h}$ (Autostrade per l'Italia, 2011) for a paver and a roller, their fuel consumption rates were expressed in ton of material laid down and compacted. The consumptions were considered to be the same for all the alternatives proposed. Indeed, even if recent studies () demonstrated the higher need of compaction of dry mixtures in the laboratory, there is no practical link between laboratory increased compaction efforts and in-situ compaction in terms of greater number of roller passages.

The airborne emissions caused by the lay down and compaction operations of bituminous layers increases with recycling rate. Therefore, the data coming from measurements performed by Jullien et al. (2006) were integrated in the process of sub-ballast installation depending on whether or not the RAP is included in the mixture formulation.

\subsubsection{Transportation of materials phase}

The crushed gravel limestone, bitumen as well as plastic big bag, steel blade and subsequently crumb rubber must be transported between the production facilities, whereas the asphalt mixtures must be transported from the hot mix production plant to the construction site. It was assumed that the materials were hauled from the quarry and plants by truck. Therefore, the environmental impacts resulting from the transportation of materials are due to the emissions released by the combustion process of the transportation vehicles. All materials were assumed to be hauled by heavy duty vehicles, and the process "GLO: Truck, Euro 3, 20-26t gross weight / 17.3t payload capacity $t s<u$-so $>$ " existing in the $C M$ database was used to determine the environmental burdens associated with the transportation of materials on the road. The extraction and processing of the fuel is included. The production of the vehicle is not included in the balancing (Gabi ts).

The different processes adopted for the case study and the transport distances $(\mathrm{T})$ considered between the different sites are outlined in Fig. 3 for the dry mixtures and Fig. 4 for the RAP mixtures. The transportation distances considered for each material used in this case study are shown in Table 4. The haul distances correspond to the estimated average from production/supply sites (quarry, bitumen refinery, tires processing plant) to the asphalt mixture plant and from this plant to the construction site.

\subsection{Life-cycle impact assessment}

The Life-Cycle impact assessment (LCIA) stage of the standardized LCA methodology comprises several steps, namely, classification, characterization, normalization, group and weighting (ISO, 2006a). Among these steps, classification and characterization were undertaken in this study.

The LCA was modeled in Gabi. The calculation of the impact category indicator results was performed at midpoint level by applying the impact assessment method ReCiPe (Goedkoop et al., 2013). Specifically, the following impact categories were considered: climate change, fossil depletion, freshwater ecotoxicity, freshwater eutrophication, human toxicity, marine ecotoxicity, marine eutrophication, metal deple-

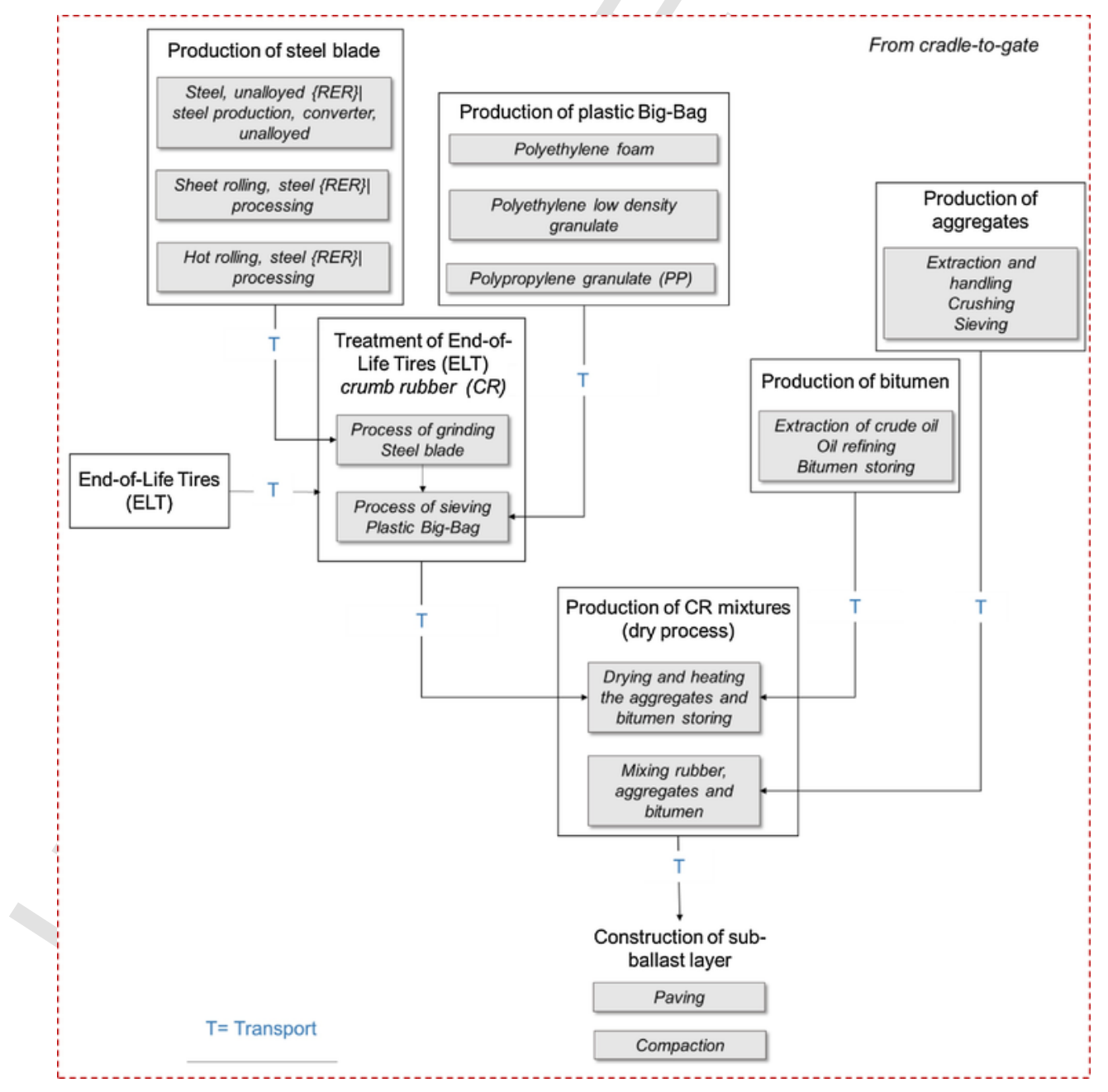

Fig. 3. Schematic representation of the processes and transportation distances adopted for the bituminous sub-ballast layer with CR. 


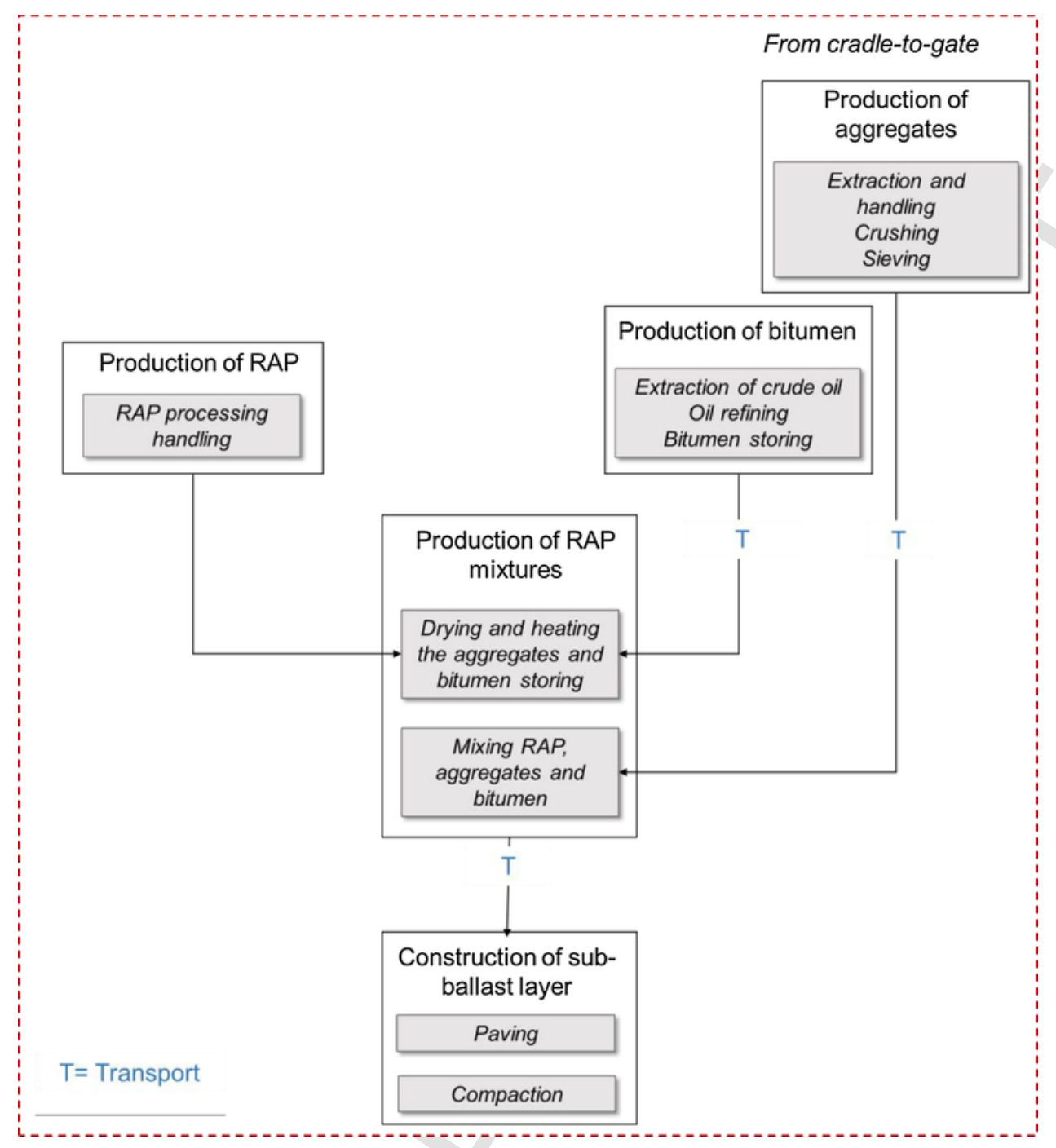

Fig. 4. Schematic representation of the processes and transportation distances adopted for the bituminous sub-ballast layer with RAP.

Table 4

Transportation distances considered in the case study and displayed in Figs. 3 and 4.

\begin{tabular}{lc}
\hline Type of material & Transport distance $[\mathrm{km}]$ \\
\hline Bituminous sub-ballast with CR (Fig. 3 ) \\
Steel blade & 286 \\
Plastic big bag & 286 \\
ELT & 60 \\
Crumb rubber & 532 \\
Bitumen & 100 \\
Aggregates & 75 \\
CR mixtures & 80 \\
Bituminous sub-ballast with RAP (Fig. 4$)$ \\
RAP & - \\
Bitumen & 100 \\
Aggregates & 75 \\
RAP mixture & 80 \\
\hline
\end{tabular}

tion, ozone layer depletion, particulate matter formation, terrestrial acidification, terrestrial ecotoxicity and water depletion.

\section{Results and discussion}

The LCA results shown in Fig. 5 highlight different aspects of the environmental performance associated with each alternative proposed for the construction of the sub-ballast layer. In particular it displays the potential relative Life-Cycle environmental impacts of the bituminous sub-ballast mixture containing CR (DRY 1.5 and DRY 2.0) for all impact categories, calculated in relation to those of the traditional bituminous sub-ballast mixture complying with RFI standard. The results are to be understood as follows: negative relative numbers mean that the alternative bituminous sub-ballast mixtures worsen the LCA results in relation to those associated with the traditional bituminous sub-ballast mixture while positive numbers represent an improvement of the environmental profile.

As it can be seen from Fig. 4 the use of bituminous sub-ballast mixtures containing crumb rubber leads to negative relative impacts in all categories, particularly in the case of the impact categories marine ecotoxicity ( $-34.35 \%$ for DRY2.0 and $-25.78 \%$ for DRY1.5), fossil depletion $(-26.91 \%$ for DRY2.0 and $-20.19 \%$ for DRY1.5), human toxicity ( -25.07 for DRY2.0 and $18.81 \%$ for DRY1.5) and freshwater ecotoxicity $(-22.59 \%$ for DRY2.0 and $-16.95 \%$ for DRY1.5). Moreover, the deterioration of the environmental profile is more pronounced when the quantity of rubber added to the mixture increases. These results can be explained by the following facts: i) the dry technology requires additional processes of crushing and treatment of the rubber in specialized plants where it is also separated from steel fibres and textile; ii) since rubber absorbs bitumen, the optimal binder content for CR mixtures is higher (i.e., 5.5 and $6 \%$ for 1.5 and $2 \%$ of CR respectively) than that for the traditional bituminous sub-ballast mixture (4\%); iii) 


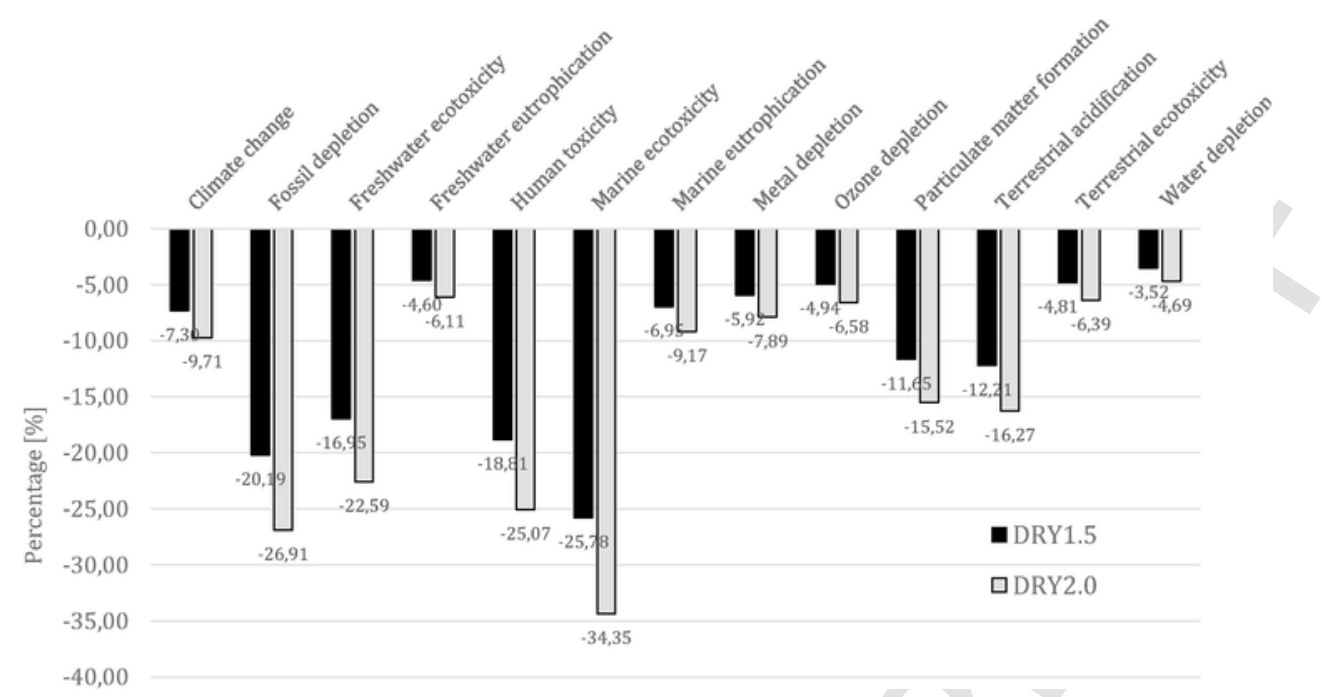

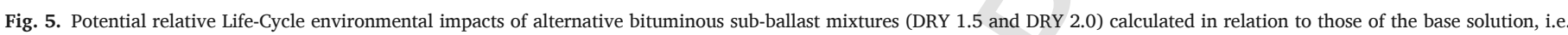
the traditional bituminous sub-ballast mixture (RFI).

the amount of recycled materials that substitutes raw materials (i.e. virgin aggregates) is relatively low ( 1.5 or $2 \%$ by weight of the mixture).

Fig. 5 shows the contributions given by the different sub-phases for the results observed in the impact categories marine ecotoxicity (Fig. 6a), that presents the greatest deterioration, and water depletion (Fig. $6 \mathrm{~b})$, that presents the lowest deterioration.

Fig. 6 confirms that the deterioration of the impact assessment results in the impact category marine ecotoxicity is essentially due to the increase of the optimal binder content for CR mixtures, which results in a higher impact in the bitumen production sub-phase. Ecotoxicity is associated to the emissions of heavy metals and hydrocarbons and their

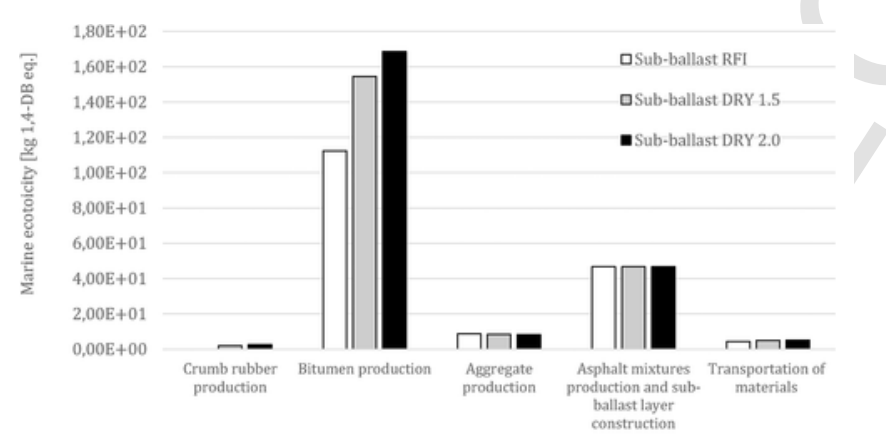

(a)

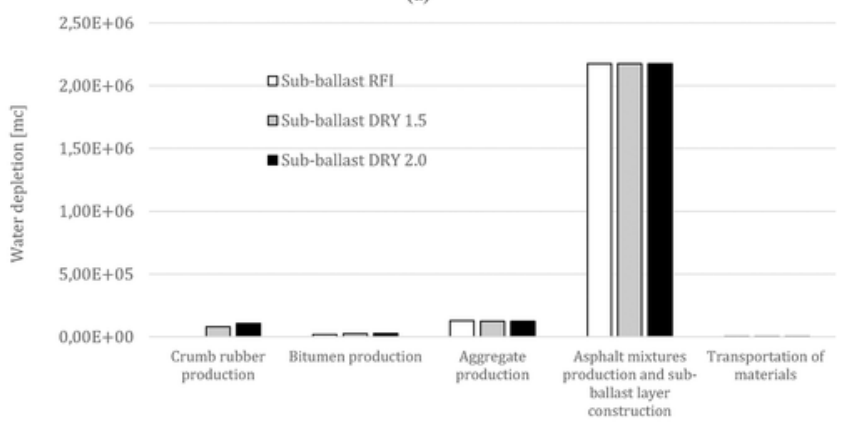

(b)

Fig. 6. Analysis of the contribution of different Life-Cycle phases and sub-phases for the results oberved in the a) marine ecotoxicity impact category and b) water depletion impact category for traditional sub-ballast mixture (RFI), sub-ballast DRY 1.5 and DRY 2.0 mixtures. adverse effect on the environment and the organisms. This includes terrestrial, marine, freshwater and human environments and all the organisms at risk from chemical exposures. As highlighted in Fig. 6 bitumen production affects significantly the ecotoxicity assessment, in particular through the emission of polycyclic aromatic hydrocarbons (PAHs) (Li et al., 2010), therefore increasing the bitumen quantity leads to the direct consequences of worsening the performance in those impacts categories. The deterioration in the water depletion category, i.e. the amount of water used for undertaking the processes underlying to the construction, is the lowest negative relative number (Fig. 5) meaning the lowest worsening effect due to the alternative solutions. The difference in the water consumption is principally due to the additional processes of crushing and treatment of the rubber in specialized plants, which results in a higher impact in the crumb rubber production sub-phase.

Fig. 7 displays the relative contribution of the several Life-Cycle phases and sub-phases to the total environmental impacts.

As detailed in Fig. 7, the asphalt mixtures production and sub-ballast layer construction phases are the main source of impacts for 9 out of 13 impact categories, followed by the bitumen production (4 out of 13 impact categories). In turn, the production of CR is responsible by the lowest share of the impact scores. In the case of the asphalt mixtures production and sub-ballast layer construction their contribution can be as high as $91.8 \%$ and $90.4 \%$ for the impact category ozone depletion, respectively in the solutions DRY1.5 and DRY2.0, while the maximum contribution given by the production of bitumen can amount to $71.4 \%$ and $73.0 \%$ for the impact category marine ecotoxicity respectively in the solutions DRY1.5 and DRY2.0. Regarding the production of CR, its maximum contribution is observed for the impact category ozone depletion, being equal to $4.4 \%$ and $5.7 \%$, respectively in the DRY1.5 and DRY2.0 solutions.

From Fig. 7 it can be concluded that for improving the environmental performance of the considered alternatives for bituminous sub-ballast (with or without $\mathrm{CR}$ ) efforts should be dedicated to optimize production and laying operations of the bituminous mixtures. It is also possible to note that crumb rubber produced using ambient grinding without chemical treatments, has a negligible impact on the overall assessment. Indeed, from Fig. 7 it emerges that crumb rubber production is not directly responsible of the higher impacts of the alternatives proposed, but the higher quantity of bitumen required for the mix design optimization of the CR bituminous mixtures leads to significant effects on all impact categories, especially the ones related to ecotoxicity. 

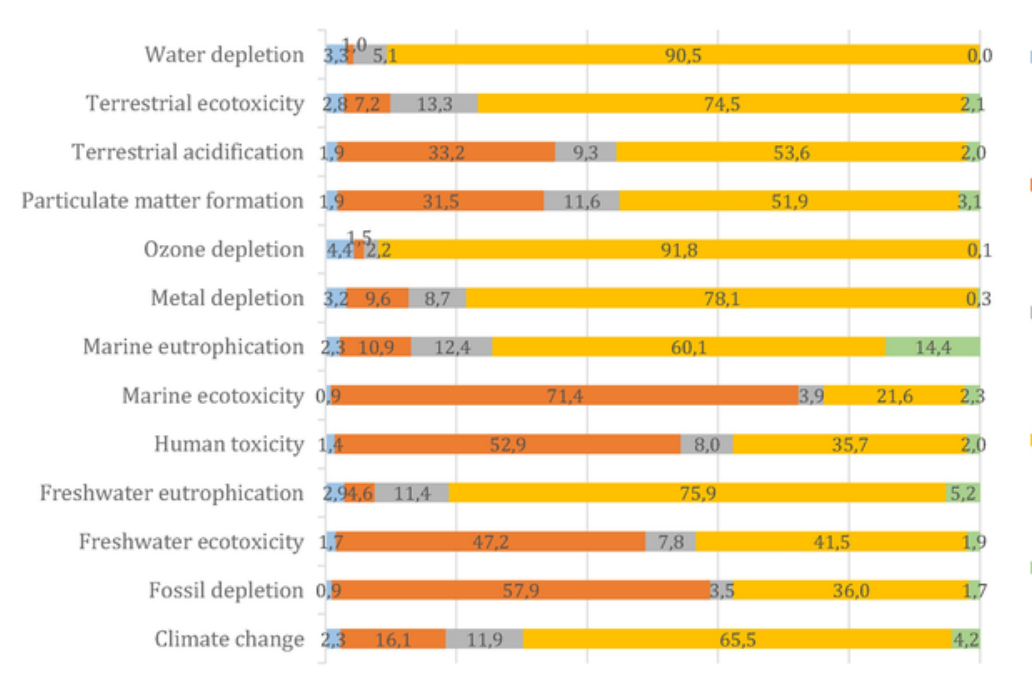

$\begin{array}{lrrr}40 & 60 & 80 & 100\end{array}$

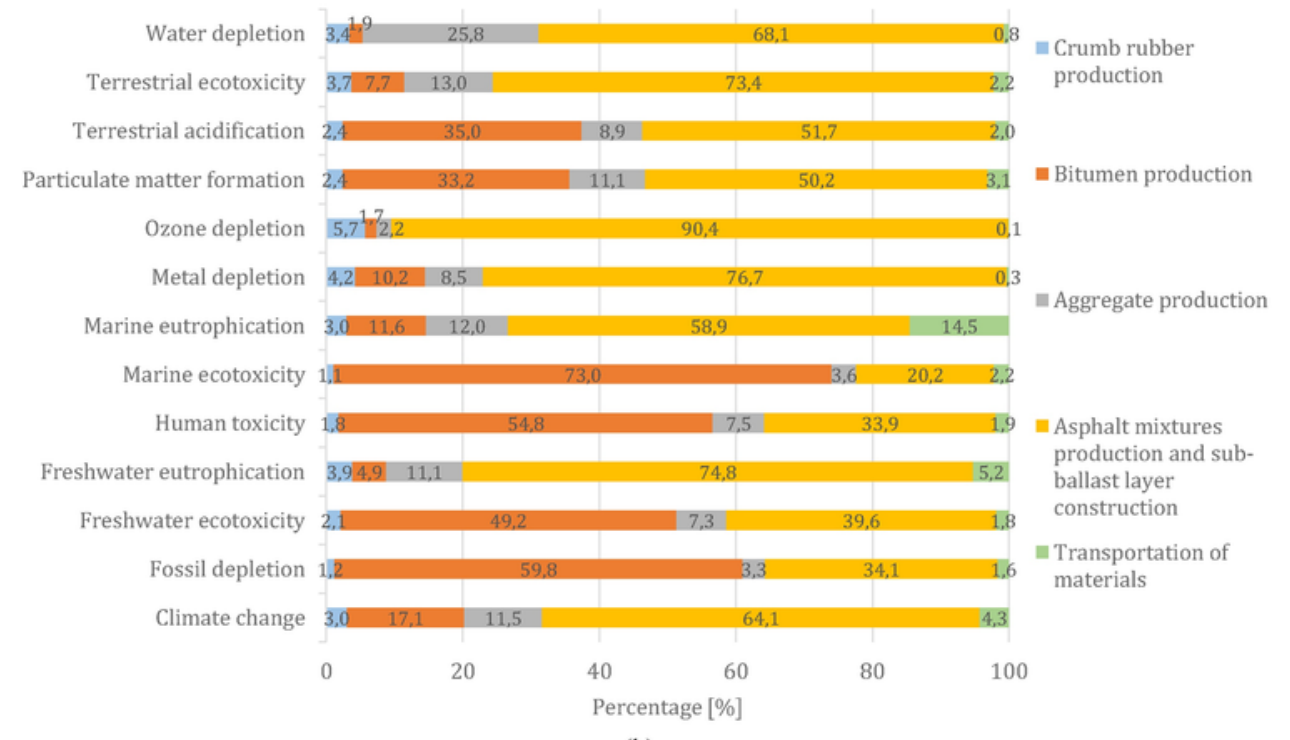

(b)

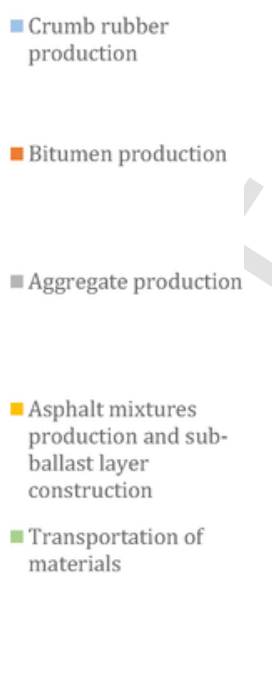

Asphalt mixtures production and subballast layer

Transportation of materials (a)

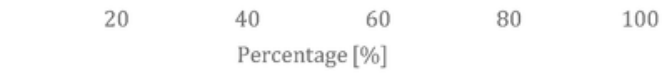

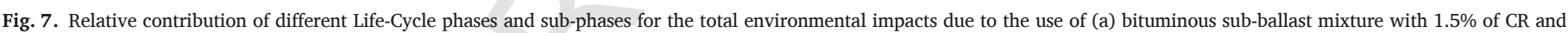
(b) bituminous sub-ballast mixture with $2.0 \%$ of CR.

Fig. 8 shows the potential relative Life-Cycle environmental impacts of the bituminous sub-ballast mixtures containing RAP (RAP30BR and RAP30FB) in relation to those of the traditional bituminous sub-ballast mixture.

The solutions containing RAP reduce the environmental impacts compared to the reference solution in all the impact categories. In particular for the solution RAP30BR, which requires a lower quantity of virgin aggregates and the same content of bitumen as that of the reference mixture, the impact categories marine eutrophication (7.67\%), climate change (4.99\%), freshwater eutrophication (4.95\%), terrestrial ecotoxicity $(4.85 \%)$ and particulate matter formation (4.80\%) show the higher benefits. It should be noted that when considering the full blending between the aged and virgin binder and reducing the quantity of virgin bitumen to be added to the mixture RAP30FB the impact categories exhibiting the higher benefits are different: marine ecotoxicity (14.20\%), marine eutrophication $(12.46 \%)$, human toxicity $(11.95 \%)$, fossil depletion (11.04\%) and freshwater ecotoxicity (10.78\%). This means that the reduction of $30 \%$ of virgin aggregates has a greater effect on certain impact categories, while the bitumen reduction allows further reductions in all the impact categories, especially in the cases of the marine ecotoxicity, fossil depletion and human toxicity.

Fig. 9 shows the contributions given by the different phases and sub-phases for the results observed in the impact categories marine eutrophication and marine ecotoxicity (Fig. 9a and b), that present the greatest improvements respectively for the mixtures RAP30BR and RAP30FB, and ozone depletion (Fig. 8c), that denotes the lowest improvement for both solutions.

Fig. 9 confirms that the environmental improvement observed in the impact category marine eutrophication is principally due to the reduction of the consumption of virgin aggregates and the reduction of their transport, while the environmental improvement in the impact category marine ecotoxicity is due to the reduction of the consumption of virgin bitumen. Marine eutrophication is characterized by the enrichment of the marine ecosystem with chemical nutrients, typically containing nitrogen $(\mathrm{N})$ and phosphorus (P) (Schindler, 2006). This may cause an elevated biomass production (Santos et al., 2018). Eutrophication impact in case of aggregate production is dominated by the processing phase (crushing and screening after) and indirect emis- 


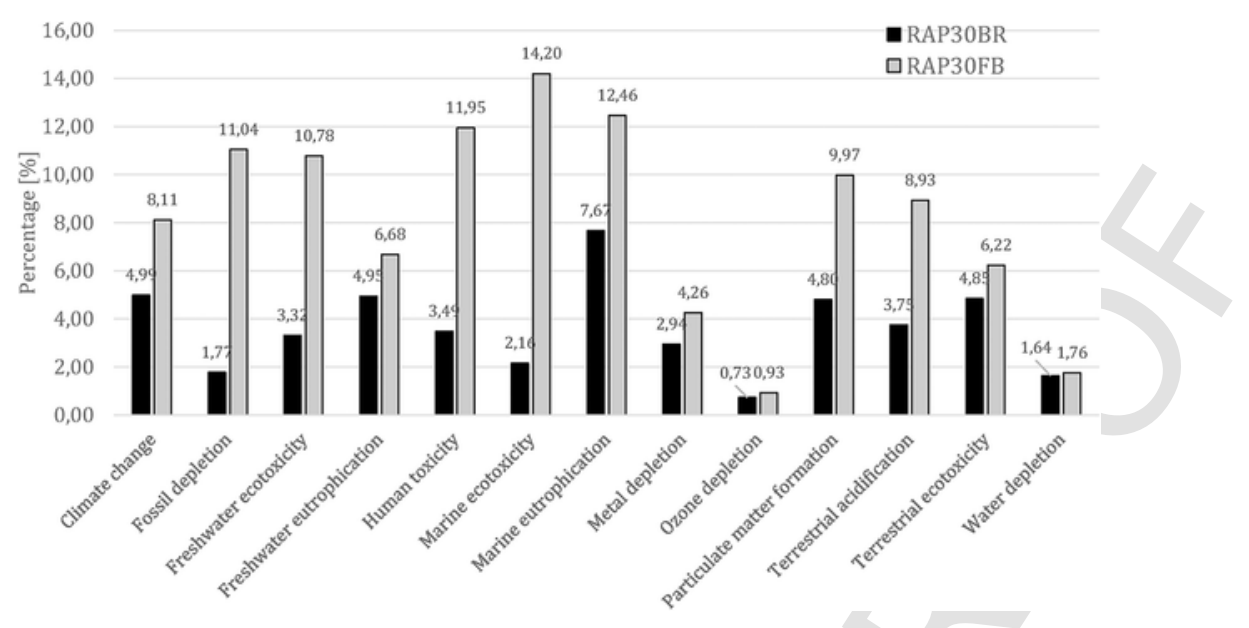

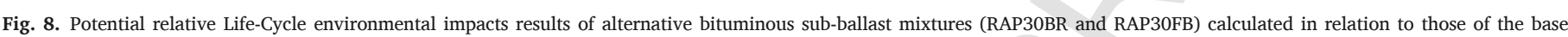
solution, i.e. the traditional bituminous sub-ballast mixture (RFI).

sions. This depends on the source of electricity supply considered (Korre and Durucan, 2009).

Moreover, from Fig. 9 it emerges again how the bitumen production affects significantly the ecotoxicity assessment. Indeed, decreasing the bitumen quantity in the bituminous mixture (RAP30FB) leads to the direct consequence of improving the performance in those impacts categories.

The production of virgin bitumen is one of the most environmental damaging and energy demanding processes, as confirmed by other recent studies (Santero et al., 2011; Santos et al., 2015; Farina et al., 2016). Therefore, the use of rejuvenators that can reactivate the aged binder is desirable, provided that the environmental impacts their production generate do not offset the benefits obtained with the reduction of the use of virgin bitumen. That seems to be the case of rejuvenators obtained from waste products, such as waste engine oil, waste engine oil bottoms, waste cooking/vegetable oil, vegetable grease, etc (Zaumanis and Mallick, 2015).

Fig. 10 shows the contribution of every phase and sub-phase to the total environmental impacts related to the construction of the sub-ballast layer when the asphalt mixtures employed contain RAP.

As detailed in Fig. 10, the asphalt mixtures production and sub-ballast layer construction phases are the main source of impacts for 11 out of 13 impact categories, followed by the bitumen production ( 2 out of 13 categories). In turn, the RAP processing is responsible by the lowest share of the impact scores (lower than $0.02 \%$ in all impact categories). In the case of the asphalt mixtures production and sub-ballast layer construction their contributions can be as high as $97.07 \%$ and $97.27 \%$ for the impact category ozone depletion, respectively in the RAP30BR and RAP30FB mixtures, while the maximum contribution given by the production of bitumen can amount to $66.79 \%$ and $62.83 \%$ for the impact category marine ecotoxicity respectively in the RAP30BR and RAP30FB mixtures. By observing Fig. 10 it can therefore be concluded that to reduce the total environmental impacts of sub-ballast layer construction the attention should be focused on reducing the impacts related to bitumen and asphalt mixtures production. The use of rejuvenators may reactivate the aged binder, thus allowing the reduction of the use of virgin bitumen. Moreover, taking into account the weight denoted by the production of asphalt mixtures for the environmental profile of the sub-ballast layer, it is then clear that the adoption of solutions that allow a reduction in the production temperature such as warm and cold mix asphalt techniques have the potential to originate substantial savings in terms of environmental impacts. Indeed, the energy consumption and emissions released to the environment are strongly related to the fabrication temperature during the mixing phase (Zaumanis et al., 2012).

\section{Summary, conclusions and perspectives}

Several research efforts are currently being undertaken to study the behavior of innovative mixtures, in which a high content of recycled materials is used in their production. Nevertheless, the extent to which those mixtures are environmentally sustainable remains to be assessed and quantified. Therefore, this paper presents a comparative LCA of a traditional bituminous mixture to be employed in the sub-ballast layer and alternative bituminous mixtures containing different percentages of recycled materials, namely RAP and CR.

Asphalt mixtures design is nowadays tailored to obtain mixtures incorporating high-content of alternative materials without under-performance. For this reason and without any clear evidence from the literature, in the analyses carried out, the durability of the different types of sub-ballast mixtures was assumed to be equal. On this basis, a LCA was performed from the resource extraction and composite materials production to the construction site, and including the transportation of materials movements, in order to highlight the principal differences among all the alternatives studied.

The results obtained showed that:

a) re-using ELTs within dry rubberized asphalt for railways sub-ballast layer is not more environmentally sustainable than using conventional asphalt mixtures. In fact:

- without a certain increase in durability, the use of CR in bituminous sub-ballast mixtures (DRY1.5 and DRY 2.0) leads to an increase of the scores in all impact categories. This is principally due to the fact that the rubber grains are obtained from crushing scrap tires in specialized plants where they are also separated from steel fibers and textile. All these operations are extra in relation to those required for producing traditional mixtures while the associated burdens are not compensated by the amount of recycled material employed (only 1.5 or $2 \%$ of $\mathrm{CR}$ ).

- due to the rubber elasticity the rubberized asphalt usually recovers deformation after the compaction phase. Therefore, by using a standard re-use of CR in asphalt mixtures, the percentage of rubber in CR mixtures cannot be increased significantly, thus the small amount used for this application does not justify all the additional consumption of resources and emissions associated with its treatment.

- for CR mixtures, the amount of bitumen increases as the amount of rubber in the mixture increases. That happens because rubber ab- 


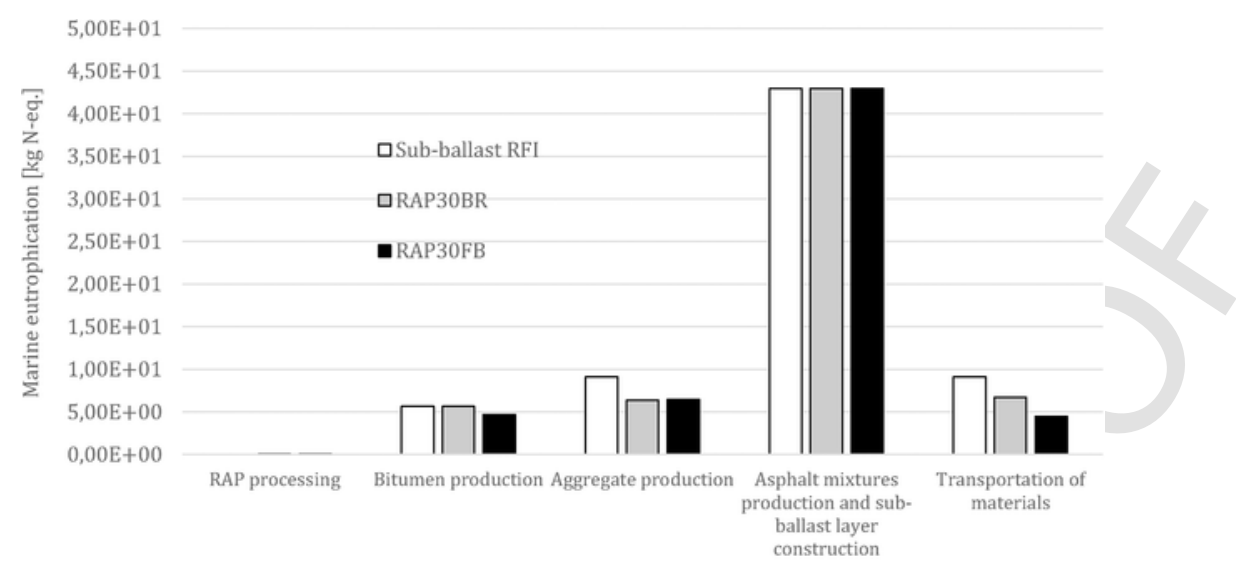

(a)

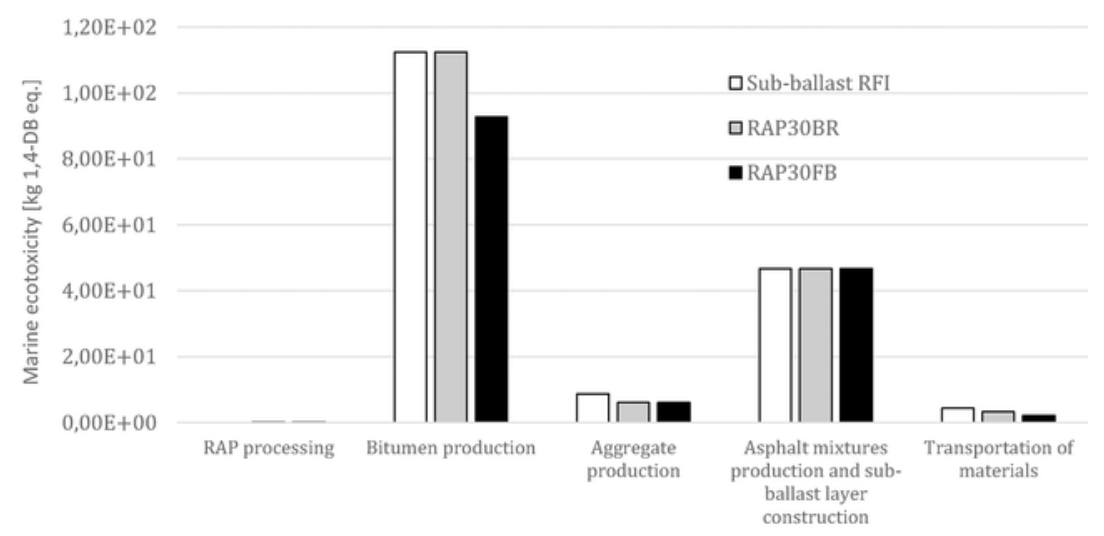

(b)

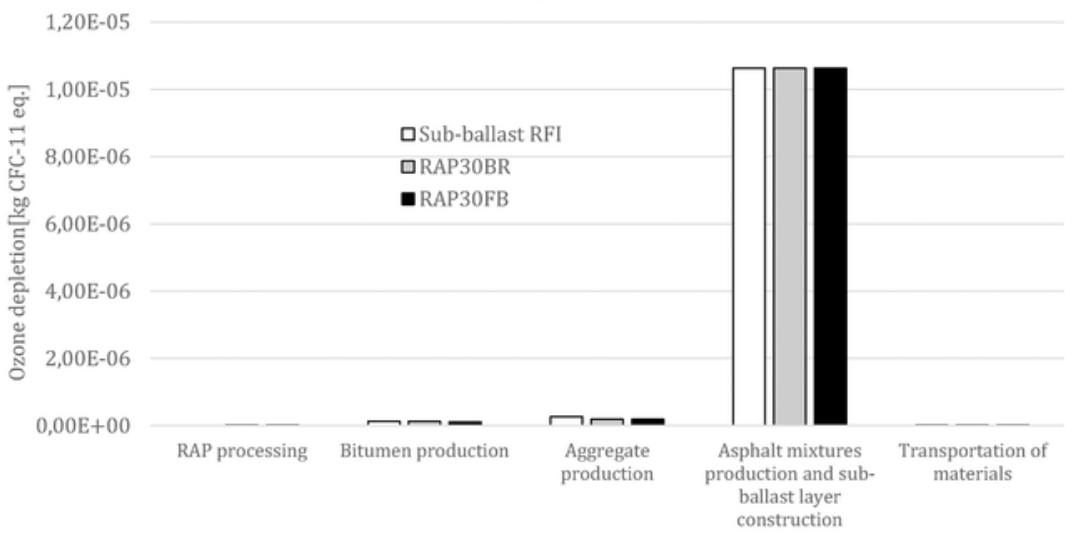

(c)

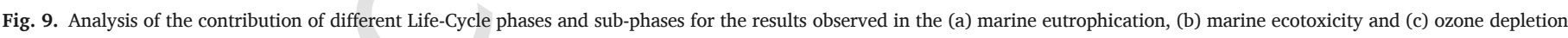
for traditional sub-ballast mixture (RFI), sub-ballast RAP30BR mixture and sub-ballast RAP30FB mixture.

sorbs the lighter parts of the bitumen in the so called process "maceration".

- The maximum contribution for CR production is observed for the impact category ozone depletion. It is possible to conclude that crumb rubber produced through ambient grinding without chemical treatments is not directly the main responsible of the higher impacts of the alternatives proposed, but the higher quantity of bitumen required for the mix design optimization of the CR bituminous mixtures leads to significant effects on all impact categories, especially the ones related to ecotoxicity. Indeed, the production of bitumen at refinery is one of the most environmental damaging and energy demanding process. b) the re-use of RAP material is a very promising application to improve the environmental sustainability of asphalt mixtures. In fact:

- mixtures containing $30 \%$ of RAP led to a reduction of the environmental impacts in all the impact categories.

- when the aged binder is fully reactivated and it is considered working as the virgin bitumen, it is possible to reduce the amount of virgin bitumen employed in a new mixture. This allows further reductions of all the resources consumed and emissions released.

- it is recommended the development and the use of rejuvenators able to reactivate the aged binder trapped in RAP, provided that the environmental impacts of their production do not offset the benefits obtained with the reduction of the use of virgin bitumen. 


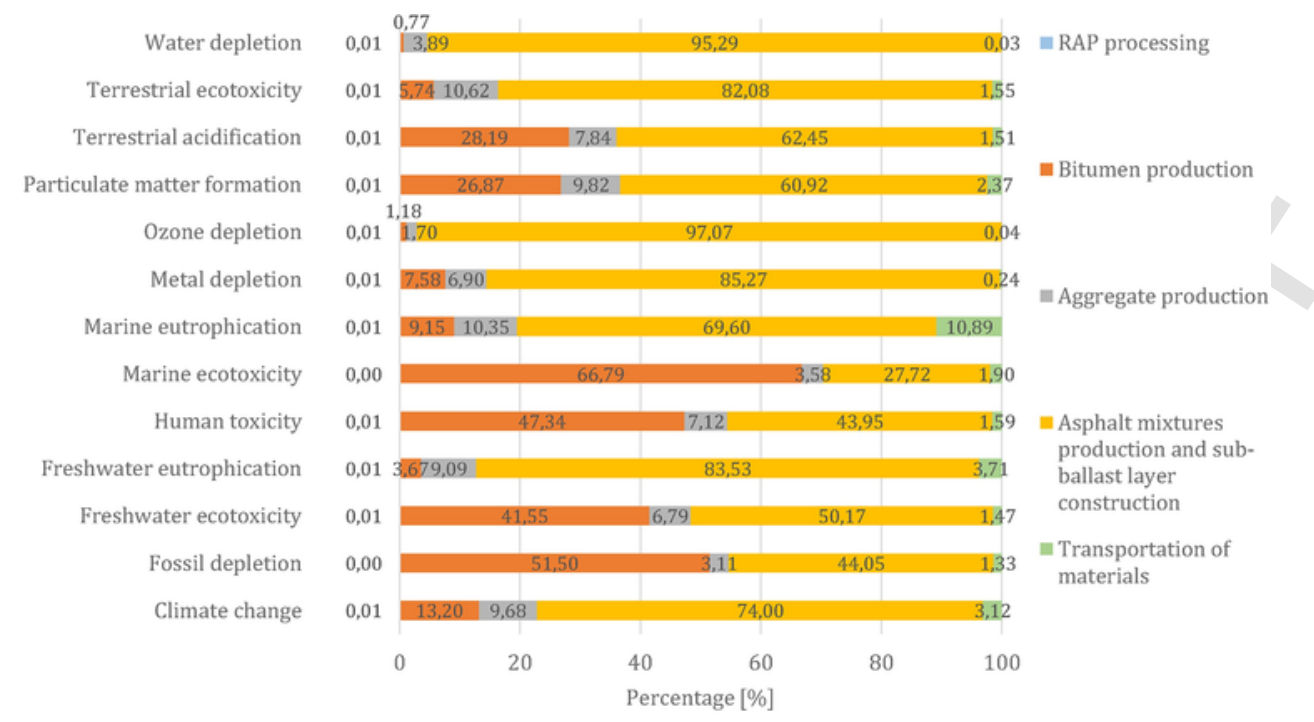

(a)

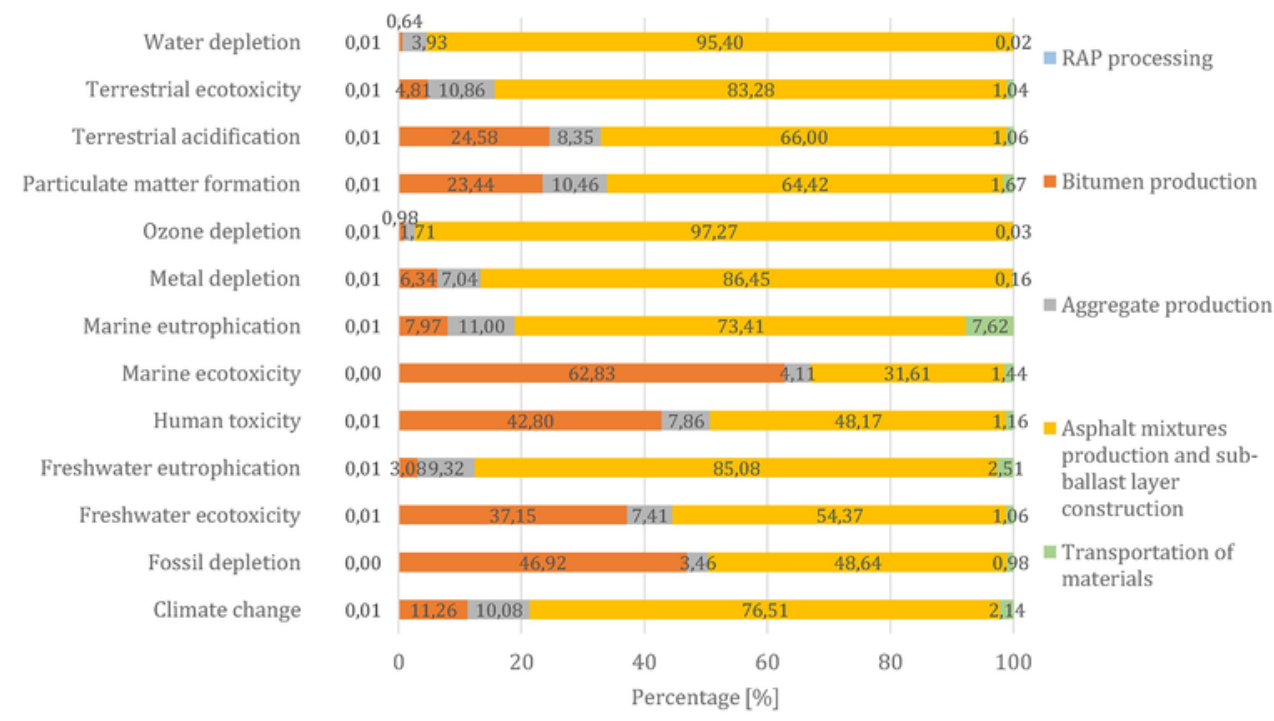

(b)

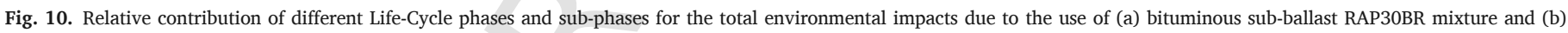
bituminous sub-ballast RAP30FB mixture.

c) for all the alternatives studied the contribution given by the asphalt mixtures production phase to the total impacts associated with the construction of the sub-ballast layer was found to be the highest. Therefore, to reduce the global environmental impacts it originates it is important to produce asphalt mixtures at lower temperatures, from which warm and cold mix asphalt techniques are examples.

Finally, the work presented in this paper offers an overview on the environmental sustainability assessment of different alternatives for bituminous sub-ballast mixtures containing different types and amounts of recycled materials intended to partially replace the use of virgin aggregates. The calculations performed were based on several context-sensitive hypothesis and thus cannot be considered neither exhaustive nor generalized. This research work opens the way to extend the study to other materials (wet technologies, rubber devulcanization treatments), evaluating for instance the possible benefits deriving from the use of rejuvenators (industrial or natural) when high RAP contents are used. Moreover, the availability of data to be used in the LCA of these type of materials is still very limited. Therefore, further research efforts should be employed to produce a more complete and robust LCI that will certainly improve the overall quality of the LCA.

\section{Conflict of interest}

The authors declare that they have no conflict of interest.

\section{Uncited references}

Crockford (1995), Feraldi et al. (2013), GaBi ts, 2017, Huang et al. (2007), RFI, 2018 and Sacramento County (1999)

\section{Acknowledgments}

The research presented in this paper was carried out as part of the Marie Curie Initial Training Network (ITN) action, FP7-PEOPLE-2013-ITN. This project has received funding from the European Union's Seventh Framework Programme for research, technological development and demonstration under grant number 607524 . 
The contents of this paper reflect the views of the authors, who are responsible for the facts and the accuracy of the data presented. Any inclusion of manufacturer names, trade names, or trademarks is for identification purposes only and is not to be considered an endorsement. Moreover, this paper does not constitute a standard, specification, or regulation.

\section{References}

Airey, G.D., Rahman, M.M., Collop, A.C., 2003. Absorption of bitumen into crumb rubber using the basket drainage method. Int. J. Pavement Eng. 4, 105.

Autostrade per l'Italia, 2011. Sustainability Report. Estimate of Emissions and CO2 Savings Derived from the Adoption of In Situ Pavement Recycling Activities (in Italian).

Bressi, S., Dumont, A.G., Partl, M., 2016. A new laboratory methodology for optimization of mixture design of asphalt concrete containing reclaimed asphalt pavement material. Mater. Struct./Materiaux et Constructions 49 (12)

Bressi, S., Colinas, N., Di Mino, G., 2017. Analytical approach for the mix design optimization of bituminous mixtures with crumb rubber. Mater. Struct. (2018) 51 (26)https:// doi.org/10.1617/s11527-018-1152-9.

Caltrans, 2006. Asphalt Rubber Usage Guide. s.l.. State of California Department of Transportation, Materials Engineering and Testing Services.

CEDEX (Centro de Estudios y Experimentación de Obras Públicas), 2007. Manual de Empleo de Caucho de NFU en Mezclas Bituminosas. Ministerio de Fomento, Ministerio de Medio Ambiente.

Chester, M.V., Horvath, A., 2009. Environmental assessment of passenger transportation should include infrastructure and supply chains. Environ. Res. Lett. 4 (024008)https: //doi.org/10.1088/1748-9326/4/2/024008, 8pp

Consoli, Frank, SETAC (Society), 1993. LCA "Code of Practice" workshop. Guidelines for Life-Cycle Assessment: a "Code of Practice", ed. 1 Society of Environmental Toxicology and Chemistry, (SETAC), Pensacola, FL.

Crockford, W.W., 1995. Recycling Crumb Rubber Modified Asphalt Pavements. s.l.. Texas Transportation Institute, Report FHWA/TX-95/1333-1F, 1995.

D'Andrea, A., Urbani, L., Bonin, G., 2004. Traffic vibration camping whit innovative materials: development and calibration of a simulation model. 27-29 October. Florence, Italy. 2th International S.I.I.V. Congress

Dong, D., Huang, X., Li, X., Zhang, L., 2012. Swelling process of rubber in asphalt and its effect on the structure and properties of rubber and asphalt. Constr. Build. Mater.

Ecopneus, 2013. Evaluation of the Carbon Footprint of the Production of Crumb Rubber from End-of-Life Tires. Ecopneus, Milano, Italia.

European Commission, 2010. General guide for life-cycle assessment - detailed guidance. Jt. Res. Centre Inst. Environ. Sustain.

European Commission, 2010. Joint research center - institute for environment and sustainability (EC, JRC - IES). International Reference Life Cycle Data System (ILCD) Handbook - General Guide for Life Cycle Assessment - Detailed Guidance, first edition, Publications Office of the European Union, Luxembourg, March 2010. EUR 24708 EN.

Farina, A., Zanetti, M., Santagata, E., Blengini, G., 2016. Life-cycle assessment applied to bituminous mixtures containing recycled materials: crumb rubber and reclaimed asphalt pavement. Resour. Conserv. Recycl. https://doi.org/10.1016/j.resconrec.2016. 10.015

Feiteira Dias, J.L., Picado-Santos, L.G., Capitão, S.D., 2014. Mechanical performance of dry process fine crumb rubber asphalt mixtures placed on the Portuguese road network. Constr. Build. Mater.

Feraldi, R., Cashman, S., Huff, M., Raahauge, L., 2013. A life-cycle assessment case study of ground rubber production from scrap tires. Int. J. Life-Cycle Assess. (2013) 18, 613-625. https://doi.org/10.1007/s11367-012-0514-8.

FHWA-RD-97-148, 1997. User Guidelines for Waste and Byproduct Materials in Pavement Construction.

Fontes, P.L., Glicerio, T., Jorge, C., Paulo, A., 2010. Evaluating permanent deformation in asphalt rubber mixtures. Constr. Build. Mater. 24, 1193

GaBi ts Software and Database Update Guide. 7.3.32017 Edition. Manual. Thinkstep Gabi.

Goedkoop, M.J., Heijungs, R., Huijbregts, M., De Schryver, A., Struijs, J., Van Zelm, R., 2013. ReCiPe 2008. A Life-Cycle Impact Assessment Method Which Comprises Harmonised Category Indicators at the Midpoint and the Endpoint Level, first edition, Report I: Characterisation.

Gowda, G.V., Hall, D.K., Elliot, R., 1996. Arkansas' Experience With Rubber Modified Mixes Using Marshall and SHRP Level I Mix Design Methods. Transportation Research Board, Washington D.C.

Huang, B., Zhang, Z., Kinger, W., 2004. Fatigue crack characteristics of HMA mixtures containing RAP. Limoges, France. Proceedings, 5th International RILEM Conference on Cracking in Pavements

Huang, Y., Bird, R., Heidrich, O., 2007. A review of the use of recycled solid waste materials in asphalt pavements. Resour. Conserv. Recycl. 52 (2007), 58-73.

ISO 14040, 2006. Environmental Management - Life-Cycle Assessment - Principles and Framework, International Organization for Standardization., Geneva.
ISO 14044, 2006. Environmental Management - Life-Cycle Assessment - Requirements and Guidelines, International Organization for Standardization., Geneva.

Jullien, A., Moneron, P., Quaranta, G., Gaillard, D., 2006. Air emissions from pavemen layers composed of varying rates of reclaimed asphalt. Resour. Conserv. Recycl. 47 (2006), 356-374.

Kandhal, P., Hanson, D., 1993. Crumb Rubber Modifier (CRM) Technologies. National Center for Asphalt Technology, Spokane, session 5, 5.15.20.

Kirk, Van, Jack, L., 1991. Caltrans experience with rubberized asphalt concrete. Topeka, Kansas, January. Presented at the Technology Transfer Session of an Introduction to Rubberized Asphalt Concrete,

Korre, A., Durucan, S., 2009. EVA025 -Final Report: Aggregates Industry Life Cycle Assessment Model: Modelling Tools and Case Studies. Waste \& Resources Action Programme.

Lee, S.L., Akisetty, C.K., Amirkhanian, S., 2008. The effect of crumb rubber modifier on the performance properties of rubberized binders in HMA pavements. Constr. Build. Mater. 22, 1368

Li, X., Xu, H., Gao, Y., Tao, Y., 2010. Comparison of end-of-life tire treatment technologies: a Chinese case study. Waste Manage. 30, 2235-2246.

Lo Presti, D., 2013. Recycled Tyre rubber modified bitumens for road asphalt mixtures: a literature review. Constr. Build. Mater.

Matthews, H., Hendrickson, C., Matthews, D., 2015. Life-Cycle Assessment: Quantitative Approaches for Decisions That Matter. Green Design Institute, Carnegie Mellon University, Pittsburgh.

McDaniel, R.S., Soleymani, H., Anderson, R.M., Turner, P., Peterson, R., 2000. Recommended use of reclaimed asphalt pavement in the SuperPave mixture design method. NCHRP Final Report. TRB, Washington, D.C, 9-12.

Olivares, F., Schultz, B., Fernández, M., Moro, B., 2009. Rubber-modified hot mix asphalt pavement by dry process. Int. J. Pavement Eng. 10, 277.

Paje, Bueno, M., Terán, F., Mirò, R., Pérez-Jiménez, F., Martínez, A.H., 2010. Acoustic field evaluation of asphalt mixtures with crumb rubber. Technical Note. Applied Acoustics.

Pinheiro, J.H.M., Soares, J.B., 2003. The effect of crumb rubber gradation and binder-rubber interaction time on the asphalt-rubber mixture (dry process). Brasilia, Brazil. Proc. of the Asphalt-Rubber Conference

Pistonesi, L., 2017. Valutazione della sostenibilità ambientale della sede ferroviaria in relazione a diverse tipologie d sub-ballast. University of Pisa.

Porot, L., Di Nolfo, M., Polastro, E., Tulcinsky, S., 2016. Life cycle evaluation for reusing reclaimed asphalt with a bio-rejuvenating agent. Prague. 6th Eurasphalt \&Eurobitume Congress

Praticò, F.G., Vaiana, R., Giunta, M., 2013. Recycling PEMs back to TLPAs: Is that possible notwithstanding RAP variability?. Appl. Mech. Mater. 253-255 (Pt. 1), 376-384.

RFI - Rete Ferroviarie Italiane. Capitolato costruzioni opere civili. sezione xv sub-ballast pavimentazioni stradali, 2016.

Ruban, A., 2012. Life-Cycle Assessment of Plastic Bag Production. Master thesis in Sustainable Development at Uppsala University, 36 pp, 30 ECTS/hp.

Sacramento County, 1999. Report on the Status of Rubberized Asphalt Traffic Noise Reduction in Sacramento County. Sacramento County and Bollard \& Brennan Inc.

Santero, N., Masanet, E., Horvath, A., 2011. Life-cycle assessment of pavements. Part I: critical review. Resour. Conserv. Recycl. 55 (9-10), 801-809.

Santos, J., Bressi, S., Cerezo, V., Lo Presti, D., 2018. SUP\&R DSS: a sustainability-based decision support system for road pavements. J. Clean. Prod.(under review).

Santos, J., Ferreira, A., Flintsch, G., 2015. A life-cycle assessment model for pavement management: road pavement construction and management in Portugal. Int. J. Pavement Eng. 16 (4), 315-336.

Sargious, M., Mushule, N., 1991. Behavior of recycled asphalt pavement at low temperatures. Can. J. Civil Eng. 18, 428-435.

Schindler, D.W., 2006. Recent advances in the understanding and management of eutrophication. Limnol. Oceanogr. 51, 356-363.

Schwarz, H., 2009. Carbon Footprint of High-Speed Railway Infrastructure (Pre-Study). International Union of Railways.

Shirodkar, P., Mehta, Y.A., Nolan, A., Sonpal, K., Norton, A., Tomlinson, C., Sauber, R., DuBois, E., 2010. A study to determine the degree of partial blending of reclaimed asphalt pavement (RAP) binder for high RAP hot mix asphalt. TRB 2010 Annual Meeting.

Shu, X., Huang, B., 2014. Recycling of waste tire rubber in asphalt and portland cement concrete: an overview. Constr. Build. Mater.

Silva, H., Oliveira, J., Jesus, C., 2012. Are totally recycled hot mix asphalts a sustainable alternative for road paving?. Resour. Conserv. Recycl. 60, 38-48.

Tam, K.K., Joseph, P., Lynch, D.F., 1992. Five-year experience of Low-temperature performance of recycled hot mix. Transportation Research Board, Washington, D.C. Transportation Research Record, No. 1362 56-65.

Turgeon, Curtis, M., 1989. The use of asphalt-rubber products in Minnesota. Kansas City, Missouri, October. Presented at the National Seminar on Asphalt-Rubber

Yu, B., Lu, Q., 2012. Life-cycle assessment of pavement: methodology and case study. Transp. Res. Part D 17, 380-388.

Zaumanis, M., Mallick, R.B., 2015. Review of very high-content reclaimed asphalt use in plant-produced pavements: state of the art. Int. J. Pavement Eng. 16 (1), 39-55.

Zaumanis, M., et al., 2012. Calculation of asphalt production energy flow to compare warm and hot mix asphalt. 13-15th June 2012, Istanbul. 5th Eurasphalt \& Eurobitume Congress 